\title{
Iron-binding proteins in sputum of chronic bronchitis patients with Haemophilus influenzae infections
}

\author{
L. Vogel*, D. Schoonbrood**+, F. Geluk*, F. Hoek++, P. Bresser+, T. Out**, H. Jansen+, \\ J. Dankert*, L. van Alphen*
}

Iron-binding proteins in sputum of chronic bronchitis patients with Haemophilus influenzae infections. L. Vogel, D. Schoonbrood, F. Geluk, F. Hoek, P. Bresser, T. Out, H. Jansen, J. Dankert, L. van Alphen. (CERS Journals Ltd 1997.

ABSTRACT: Airway inflammation during infection is associated with increased transudation of serum proteins and increased production of protein by the airway epithelium. We therefore, assessed whether Haemophilus influenzae infections in patients with chronic bronchitis are associated with increased levels of transferrin and lactoferrin in the sputum compared to uninfected patients.

Sputum sol phase and serum samples from 14 infected and 13 uninfected patients with chronic bronchitis and from 12 bronchial asthma patients were included in the study.

The median Q-values (the concentration in sputum sol phase/the concentration in serum) $\times 10^{3}$ of transferrin appeared increased in chronic bronchitis patients with an $H$. influenzae infection $(\mathbf{2 6 . 0}, \mathrm{n}=13)$ compared to uninfected controls $(9.5$, $n=11$ ) and bronchial asthma patients $(4.5, n=6)$. The ratio of the $Q$ (transferrin) $/ Q$ (albumin) was $>1$ in infected chronic bronchitis patients, indicating local production of transferrin. Growth of $\boldsymbol{H}$. influenzae was stimulated more in sputum from infected and uninfected patients with chronic bronchitis than in sputum from patients with bronchial asthma. The concentrations of lactoferrin were not significantly different in infected $(n=14)$ and uninfected $(n=13)$ chronic bronchitis patients and bronchial asthma patients $(\mathrm{n}=12)\left(\right.$ median $137.4,84.6,87.1 \mathrm{mg} \cdot \mathrm{L}^{-1}$, respectively).

We conclude that in patients with chronic bronchitis with Haemophilus influen$z a e$ infections, the levels of transferrin are increased and the levels of lactoferrin are not associated with infections.

Eur Respir J 1997; 10: 2327-2333.
Depts of *Medical Microbiology, **Clinical Immunology, + Pulmonology and ${ }^{++}$Clinical Chemistry, Academic Medical Center, Amsterdam, The Netherlands

Correspondence: L. van Alphen

Academic Medical Center

Dept of Medical Microbiology

Room L1-162

Meibergdreef 15

1105 AZ Amsterdam

The Netherlands

Keywords: chronic bronchitis

Haemophilus influenzae

iron binding proteins

Received: April 21997

Accepted after revision 16 May 1997

This work was financially supported by the Netherlands Asthma Foundation (grant no. 91.18). D.S. was supported by Fisons Pharmaceuticals.
Nonencapsulated Haemophilus influenzae causes persistent infections in the lower respiratory tract of patients with chronic bronchitis [1,2], despite the presence of polymorphonuclear leucocytes, specific antibodies [3] and complement. Since H. influenzae does not persist in the lower respiratory tract of patients with bronchial asthma and healthy individuals, the local conditions in the bronchial lumen of patients with chronic bronchitis during infection may be beneficial for the survival and growth of $H$. influenzae. Proteins and other factors in the bronchial lumen originate from the tissue fluids by transudation through the epithelial layer, or are produced by the respiratory epithelium or the inflammatory cells in the respiratory tract [4]. Local inflammation of the lower respiratory tract, one of the characteristics of chronic bronchitis, is stimulated by bacterial components, and mediators from inflammatory cells. Moreover, it is associated with increased transudation of serum proteins [4-8] and increased production of proteins by the airway epithelium [2]. Among these proteins are the iron-binding proteins transferrin and lactoferrin. Since $H$. influenzae has an absolute requirement for haem and iron, and the concentrations of free iron in body fluids are low [9], H. influenzae needs other sources of iron, such as transferrin and lactoferrin [9-11]. Transferrin is mainly a serum protein and lactoferrin is produced locally within the lung by the serous cells of the bronchial epithelium [12], but also by neutrophilic granulocytes [13].

The aim of this study was to determine whether the amounts of the iron-binding proteins, transferrin and lactoferrin, in the sputum sol phase are increased in chronic bronchitis patients with an $H$. influenzae infection compared to uninfected chronic bronchitis patients and those with bronchial asthma. To determine whether transferrin originates only from transudation from the blood in these patients, the levels of transferrin were compared with the levels of serum albumin, having a similar molecular weight and thereby a similar transudation [4]. The local production of lactoferrin was compared with that of secretory immunoglobulin A ( $\operatorname{Ig} \mathrm{A})$, which is also locally produced by epithelial cells [14-16].

We show that increased amounts of transferrin, but not lactoferrin, were found in the sputum sol phase of chronic bronchitis patients with an $H$. influenzae infection compared to uninfected patients with chronic bronchitis and patients with bronchial asthma. Transferrin was shown to originate partly from transudation but also 
from local production or active transport. In addition, $H$. influenzae grew better in the sputum sol phase of patients with chronic bronchitis than in the sputum sol phase of patients with bronchial asthma.

\section{Materials and methods}

\section{Patients}

All patients were selected from the out-patient clinic of the Dept of Pulmonology of the Academic Medical Center of the University of Amsterdam. Fourteen chronic bronchitis patients with an infection caused by nonencapsulated $H$. influenzae (mean age 56 yrs, range 2182 yrs), 13 chronic bronchitis patients without an infection (mean age 59 yrs, range 39-77 yrs) and 12 patients with bronchial asthma (mean age 48 yrs, range 28-66 yrs) were included in the study. Patients were diagnosed as having chronic bronchitis according to the definition of the Medical Research Council (MRC) [17] or bronchial asthma according to the American Thoracic Society (ATS) criteria [18]. Four of the chronic bronchitis patients with an $H$. influenzae infection, four of the uninfected chronic bronchitis patients and four of the patients with bronchial asthma were smokers. The patients were not treated with antibiotics for at least 2 weeks before sampling or inhaled or systemic corticosteroids at least 6 weeks before sampling. All patients with chronic bronchitis had a history of $H$. influenzae infections. The presence of $H$. influenzae was assessed by culturing a sputum sample on chocolate agar and by immunochemical staining of a smear of sputum with specific monoclonal antibody 8BD9 [19].

\section{Serum and sputum samples}

Sputum samples and venous blood samples from each patient were collected on the same day. Sputum samples were partly used for bacteriological culture. The remainder was centrifuged for $90 \mathrm{~min}$ at 50,000 $\times \mathrm{g}$ and the supernatant was stored as the sputum sol phase. Sputum sol phase and serum were stored at $-20^{\circ} \mathrm{C}$.

\section{Determination of the concentrations of various proteins in serum and sputum samples}

The concentrations of transferrin in paired serum and sputum sol phase samples were quantified immunochemically on a Behring Nephelometer Analyser (Behring Werke AG, Marburg, Germany) using standards and specific antiserum from Behring. This method appeared valid for measuring concentrations of transferrin in sputum sol phase since the mean (SD) recovery of protein standard serum added to sputum sol phase samples containing transferrin in the relevant range $25-250 \mathrm{mg} \cdot \mathrm{L}^{-1}$ was $95.7 \pm 4.26 \%(n=5)$.

The concentration of albumin in the serum and sputum sol phase samples was determined by immunoturbidimetry with the use of a Cobas Bio Analyser [20]. Antialbumin, code A001, was obtained from DAKO (Glostrup, Denmark). A standard serum for nephelometry (Behring 07, Behring Werke AG) and a serum with a known concentration of albumin were included for reference.
The concentrations of lactoferrin in sputum sol phase were determined with an enzyme-linked immunosorbent assay (ELISA) as described by VAN DE GRAAF et al. [14]. Microtitre plates were coated with antibodies to lactoferrin from DAKO (A186) and bound lactoferrin was determined with peroxidase-conjugated rabbit-antihuman lactoferrin. The concentrations of sIgA in sputum sol phase samples were determined with an ELISA performed as described by HAAIJMAN et al. [21]. In short, microtitre plates were coated with goat-anti-mouse polyclonal immunoglobulins (GM17-03-D02) from the Central Laboratory of the Red Cross Blood Transfusion Service (Amsterdam, The Netherlands), and subsequently coated with mouse antibodies to the secretory component of IgA. After incubation with dilutions of the sputum sol phase samples, sIgA was detected by horse radish peroxidase-conjugated anti-IgA (DAKO P216). With the methods used for quantifying the concentrations of lactoferrin and $\operatorname{sg} \mathrm{A}$, the intra- and inter-assay coefficients of variation are low and the recovery of exogenously added lactoferrin and SIgA in sputum samples is high [22].

\section{Calculation to determine whether transferrin is transu- dated or locally produced}

The relationship between the concentrations of transferrin $(79,550 \mathrm{M})$ and albumin $(68,000 \mathrm{M})$ in serum and sputum sol phase was expressed by the ratio Q which is (the concentration in sputum sol phase/ the concentration in serum) $\times 10^{3}[4,23]$, following the principle described by Felgenhauer [24]. Subsequently, the relative coefficient of excretion (RCE) of transferrin relative to albumin was calculated as the ratio $Q$ transferrin/Q albumin to determine whether transferrin was produced locally. Since both proteins have similar molecular weight and albumin is only released by transudation, this RCE is approximately 1 when transferrin is derived from transudation. Higher ratios indicate local production or active transport of transferrin [4, 16]. This RCE-value is independent of the variable dilution of proteins in the sputum sol phase of the individual samples.

\section{Growth of H. influenzae in sputum sol phase}

$H$. influenzae strain $\mathrm{d} 1$, being streptomycin resistant, was grown on chocolate agar plates supplemented with nicotinamide adenine dinucleotide (NAD) (10 mg. $\mathrm{L}^{-1}$, Sigma N7381, Zwijndrecht, the Netherlands) and haemin $\left(10 \mathrm{mg} \cdot \mathrm{L}^{-1}\right.$, Sigma $\left.\mathrm{H} 2250\right)$ at $37^{\circ} \mathrm{C}$ in a humid atmosphere containing $5 \% \mathrm{CO}_{2}$, subsequently inoculated in Brain Heart Infusion Broth (BHI: Difco Laboratories, Detroit, MI, USA) containing $100 \mu \mathrm{M}$ ethylenediamine di-ortho-phenylacetic acid (EDDA, Sigma E4135) and protoporphyrin IX (2 $\mu \mathrm{g} \cdot \mathrm{mL}^{-1}$, Sigma P5889) and cultured in this iron-deficient medium at $37^{\circ} \mathrm{C}, 5 \% \mathrm{CO}_{2}$ for at least $2 \mathrm{~h}$ under shaking. Ten microlitres of the bacterial suspension and $10 \mu \mathrm{L}$ of distilled water was added to $80 \mu \mathrm{L}$ of sputum sol phase in microtitre plates. All cultures were performed in triplicate for $16 \mathrm{~h}$. Growth was measured at $540 \mathrm{~nm}$ with an ELISA-reader (Anthos Labtec Instruments, Salzburg, Austria). As a control 
for the depletion of free iron in the medium, the lack of bacterial growth in iron-limited medium after $16 \mathrm{~h}$ was determined. The iron limitation could be reversed by the addition of $\mathrm{FeCl}_{3}(120 \mu \mathrm{M})$.

\section{Determination of the total iron content of sputum sol phase}

The total iron content of sputum sol phase was determined with atomic absorption spectrometry with a graphite furnace using an atomic absorption spectrophotometer (model 2100; Perkin Elmer, Foster City, CA, USA).

\section{Statistical analysis}

The results were expressed as medians. For statistical analysis of the differences between protein concentrations in sputum sol phase, the Qprotein, the RCE of transferrin of the three groups of patients, the growth stimulation of $H$. influenzae in sputum sol phase and the total iron content of sputum sol phase, the nonparametric Wilcoxon rank sum test was used since the data had a wide range and were not normally distributed [25]. To determine the significance of the local production of transferrin the Student's t-test was used. The correlation between the concentrations of lactoferrin and $\operatorname{sIg}$ A was assessed with the Spearman rank test [25]. A p-value of less than 0.05 was considered statistically significant.

\section{Results}

\section{Transudation and local production of transferrin}

The concentrations of transferrin in the sputum sol phase of chronic bronchitis patients with an $H$. influenzae infection (median $60.0 \mathrm{mg} \cdot \mathrm{L}^{-1}, \mathrm{n}=13$ ) were increased compared to those in the sputum sol phase of uninfected patients with chronic bronchitis (median 23.2 $\mathrm{mg} \cdot \mathrm{L}^{-1}, \mathrm{n}=11, \mathrm{p}=0.026$ ) or bronchial asthma (median $10.8 \mathrm{mg} \cdot \mathrm{L}^{-1}, \mathrm{n}=6, \mathrm{p}=0.002$ ) (fig. 1 ). The concentrations of transferrin in the sputum sol phase of uninfected patients with chronic bronchitis or bronchial asthma were not significantly different $(\mathrm{p}=0.079)$.

The Qtransferrin, expressing the ratio of the concentration of transferrin in sputum sol phase over the concentration of transferrin in serum, was increased for the chronic bronchitis patient group with an $H$. influenzae infection (median 26.0, $\mathrm{n}=13$ ) compared to the chronic bronchitis patient group without an infection (median 9.5, $\mathrm{n}=11, \mathrm{p}=0.02$ ) and the bronchial asthma patient group (median 4.5, $\mathrm{n}=6, \mathrm{p}=0.001$ ) (fig. 2a). The Qtransferrin values of uninfected patients with chronic bronchitis or bronchial asthma were not different.

To determine whether transferrin in sputum originates only from transudation, the Qtransferrin was compared with the Qalbumin, since albumin is a serum protein that is supposed to reach the mucosa by transudation. The Qalbumin was also significantly increased in the chronic bronchitis patient group with an $H$. influenzae infection (median 13.1, $\mathrm{n}=14$ ) in comparison with the chronic bronchitis patient group without an infection (median 5.5, $\mathrm{n}=13, \mathrm{p}=0.02$ ) and the bronchial asthma patient

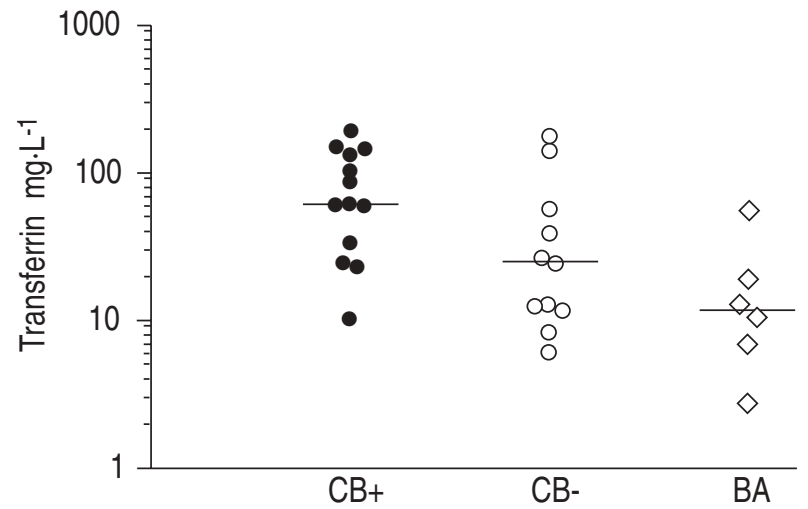

Fig. 1. - Concentrations of transferrin in the sputum sol phase of chronic bronchitis patients with $(\mathrm{CB}+; \bullet)$ and without $(\mathrm{CB}-; \mathrm{O})$ a Haemophilus influenzae infection and patients with bronchial asthma $(\mathrm{BA} ; \gg)$. The median value is indicated for each group.

group (median 7.7, $\mathrm{n}=12, \mathrm{p}=0.03$ ) (fig. 2b). The Q-values of albumin for the chronic bronchitis patient group without an infection and for the bronchial asthma patient group were not different (fig. 2b). The RCE for transferrin relative to albumin, was calculated as the ratio Qtransferrin/Qalbumin. The RCE for transferrin had a median value of 1.0 both in the chronic bronchitis patient group without an infection $(\mathrm{n}=11)$ and in the bronchial asthma patient group $(n=6)$ (fig. 3 ). These results indicate that transferrin arrived in the sputum sol phase of these patients by transudation in a way similar to albumin. In contrast, the RCE for transferrin in chronic bronchitis patients with an $H$. influenzae infection had
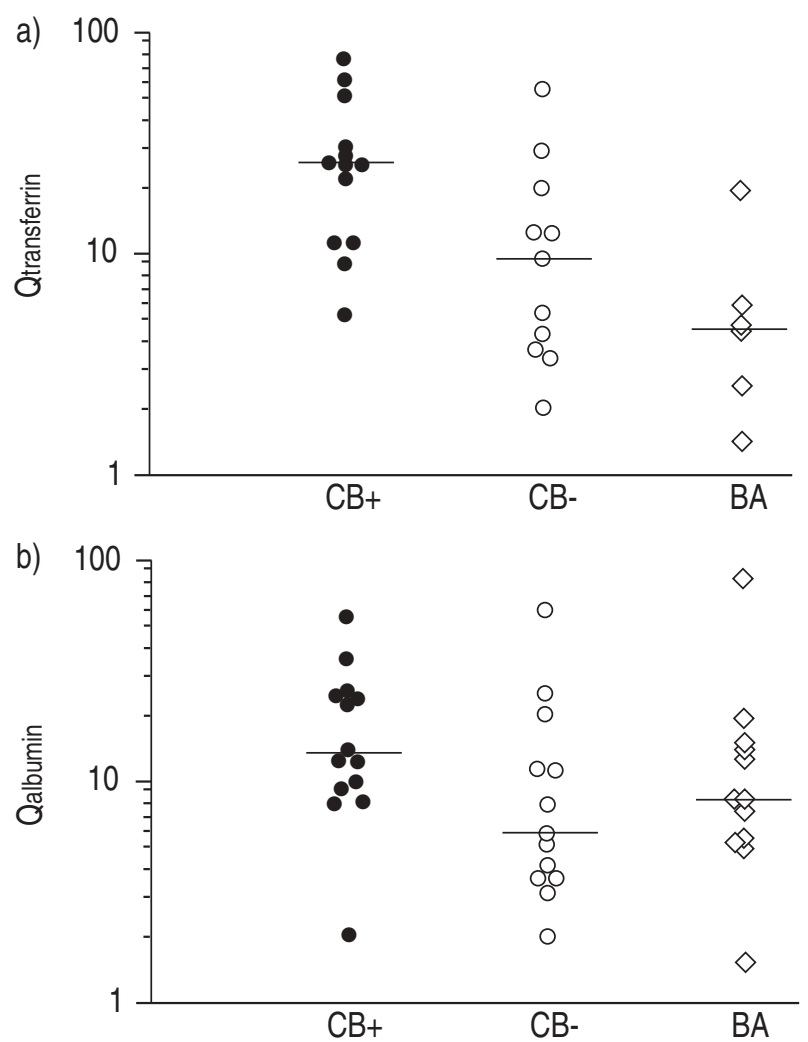

Fig. 2. - Individual Q-values for: a) transferrin; and b) albumin in chronic bronchitis patients with $(\mathrm{CB}+; \bullet)$ and without $(\mathrm{CB}-; \mathrm{O})$ a Haemophilus influenzae infection and patients with bronchial asthma $(\mathrm{BA} ; \gg)$. The median value is indicated for each group. 


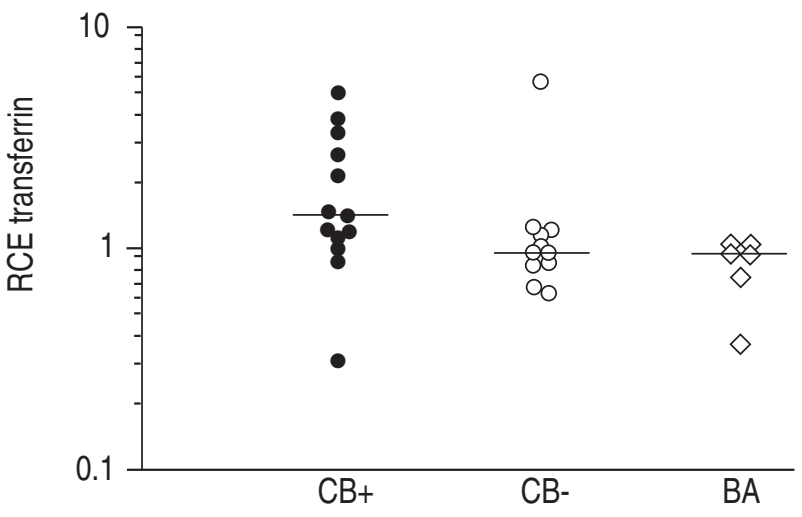

Fig. 3. - Individual relative coefficients of excretion (RCEs) for transferrin in chronic bronchitis patients with $(\mathrm{CB}+; \bullet)$ and without (CB-; O) a Haemophilus influenzae infection and patients with bronchial asthma (BA; ). The median value is indicated for each group.

a median value of $1.4(\mathrm{n}=13 ; 95 \%$ confidence interval 1.13-3.34) (fig. 3). This value is significantly higher than calculated for chronic bronchitis patients without an infection $(\mathrm{p}=0.03)$ and patients with bronchial asthma $(\mathrm{p}=0.01)$ and also significantly higher than $1(\mathrm{p}<0.01)$. Therefore, transferrin transudates and is produced locally during infections with $H$. influenzae.

To exclude the possibility that the results were influenced by degradation of transferrin or albumin in the sputum and serum samples, the effect of overnight incubation of two sputum and two serum samples at $37^{\circ} \mathrm{C}$ on the levels of transferrin and albumin was measured. In sputum samples, the recovery after overnight incubation of transferrin was $105.5 \pm 18.0 \%$ and of albumin $104.1 \pm 0.2 \%$. In serum samples, the recovery of transferrin was $96.2 \pm 4.9 \%$ and of albumin $108.0 \pm 3.5 \%$.

\section{Growth stimulation of $\mathrm{H}$. influenzae in sputum sol phase}

To evaluate the relevance of the high levels of transferrin in the sputum sol phase of chronic bronchitis patients with an $H$. influenzae infection, $H$. influenzae was grown in sputum sol phase samples of infected $(n=5)$ and uninfected $(n=4)$ chronic bronchitis patients and in the sputum sol phase samples of patients with bronchial asthma $(n=5)$. The optical density $(O D)$ at 540 $\mathrm{nm}$ measured after $16 \mathrm{~h}$ of growth is shown in figure 4. H. influenzae grew significantly better in the sputum sol phase of chronic bronchitis patients with an $H$. influenzae infection $(\mathrm{p}=0.014)$ and in the sputum sol phase of uninfected chronic bronchitis patients $(\mathrm{p}=0.043)$ than in the sputum sol phase of patients with bronchial asthma. The growth stimulation in sputum sol phase of infected and uninfected patients with chronic bronchitis was not significantly different.

To promote bacterial growth, the increased levels of transferrin have to increase the potential iron supply. Therefore, the total iron content of sputum sol phase from six patients with chronic bronchitis and 12 patients with bronchial asthma was determined. The total iron content of sputum sol phase of patients with chronic bronchitis (median $36.8 \mu \mathrm{g} \cdot \mathrm{L}^{-1}$ ) was significantly higher $(\mathrm{p}<0.001)$ than the total iron content of sputum sol phase of patients with bronchial asthma (median 14.7 $\left.\mu \mathrm{g} \cdot \mathrm{L}^{-1}\right)$.

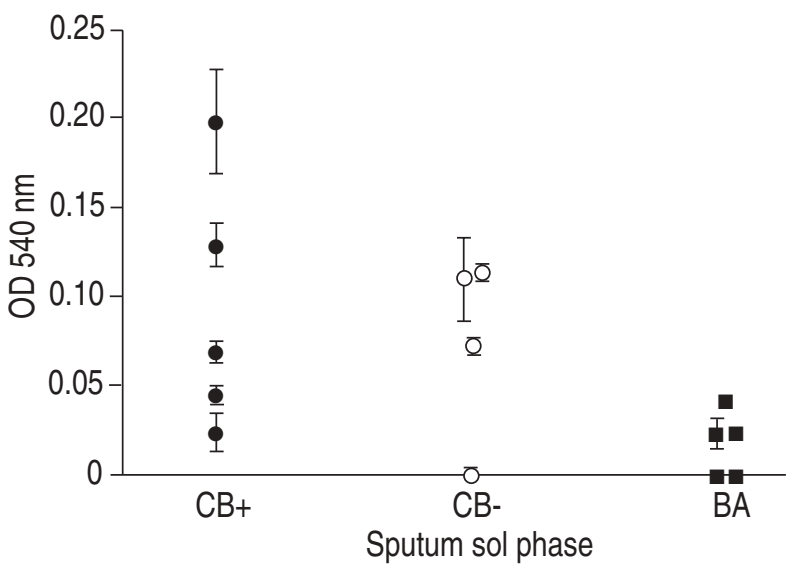

Fig. 4. - Growth of Haemophilus influenzae in sputum sol phase of infected $(\mathrm{CB}+; \bullet, \mathrm{n}=5)$ and uninfected $(\mathrm{CB}-; \circ, \mathrm{n}=4)$ patients with chronic bronchitis and in sputum sol phase of patients with bronchial asthma (BA; $\mathbf{m}, \mathrm{n}=5)$. Growth was determined by optical density measurements $(\mathrm{OD})$ at $540 \mathrm{~nm}$ after $16 \mathrm{~h}$. Values are mean \pm SD.

\section{Local production of lactoferrin and $\operatorname{sigA}$}

The concentrations of lactoferrin in the sputum sol phase of individual patients and the median values are shown in figure 5. The concentrations of lactoferrin in the sputum sol phase of chronic bronchitis patients with $(\mathrm{n}=14)$ and without an $H$. influenzae infection $(\mathrm{n}=13)$ and of patients with bronchial asthma $(\mathrm{n}=12)$ (median $137.4,84.6,87.1 \mathrm{mg} \cdot \mathrm{L}^{-1}$, respectively) were not significantly different, although the median in the first group
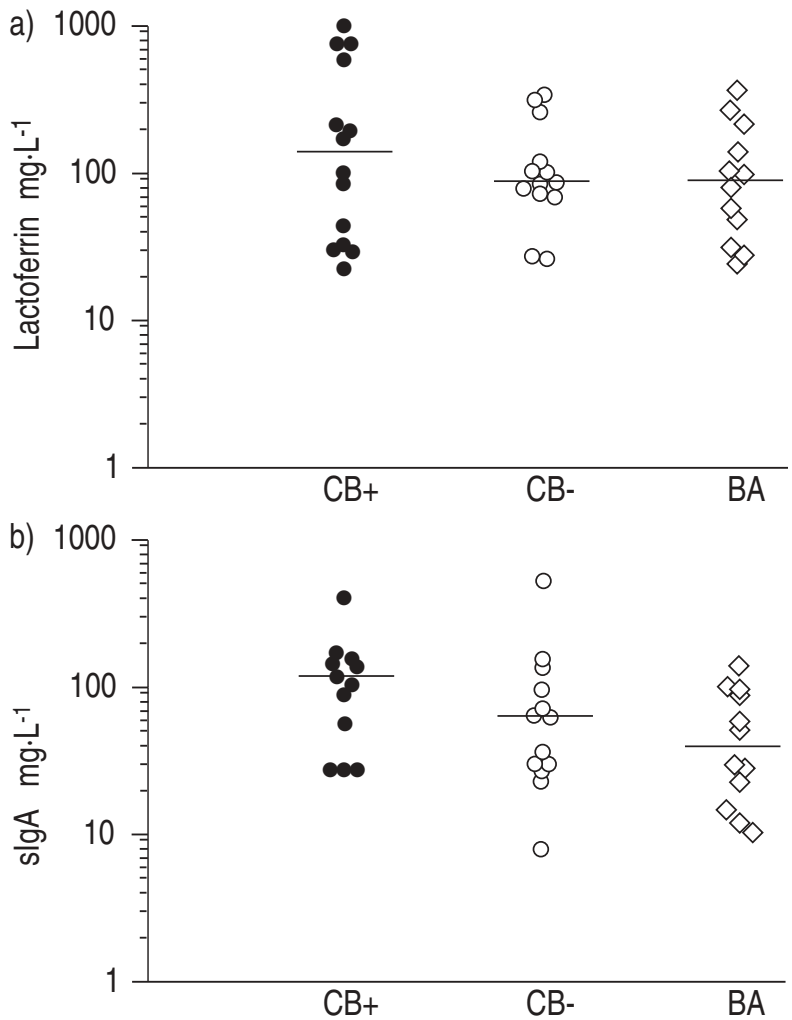

Fig. 5. - Concentrations of: a) lactoferrin; and b) secretory immunoglobulin A (sIgA) in the sputum sol phase of chronic bronchitis patients with $(\mathrm{CB}+; \bullet)$ and without $(\mathrm{CB}-; \mathrm{O})$ a Haemophilus influenzae infection and patients with bronchial asthma (BA; ). The median value is indicated for each group. 


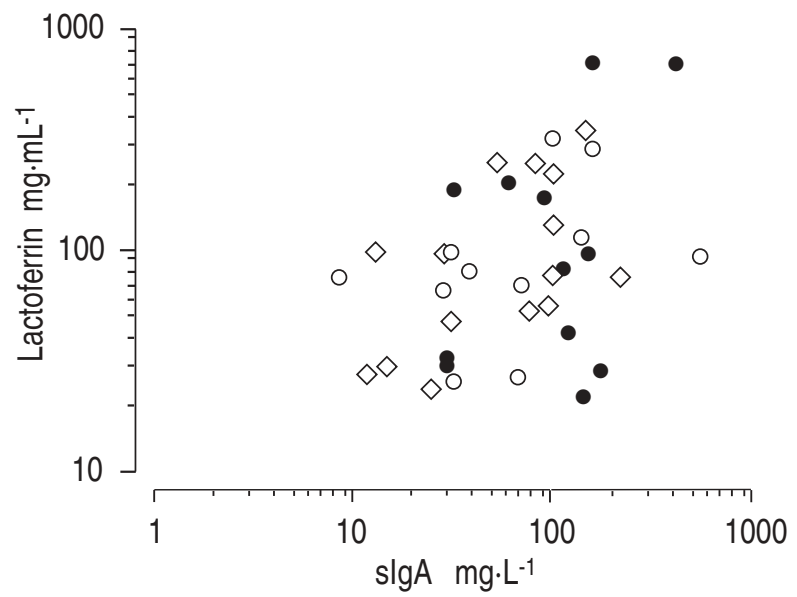

Fig. 6. - The individual concentrations of surface immunoglobulin A $(\operatorname{sig} \mathrm{A})$ in relation to the concentrations of lactoferrin in the sputum sol phase of chronic bronchitis patients with $(\mathrm{CB}+; \bullet)$ and without (CB-; O) a Haemophilus influenzae infection and patients with bronchial asthma (BA; ).

was much higher. The lack of significant differences was due to a wide spread in the individual levels of lactoferrin, especially in the chronic bronchitis patient group with an $H$. influenzae infection. The sIgA concentrations are shown in figure $5 \mathrm{~b}$. In patients with chronic bronchitis who had an $H$. influenzae infection, the concentrations of sIgA in sputum sol phase samples (median $117.5 \mathrm{mg} \cdot \mathrm{L}^{-1}, \mathrm{n}=12$ ) were significantly increased compared to patients with bronchial asthma (median $\left.41.7 \mathrm{mg} \cdot \mathrm{L}^{-1}, \mathrm{n}=12, \mathrm{p}=0.01\right)$. The concentrations of sIgA in sputum sol phase samples of patients with bronchial asthma were similar to the concentration of sIgA in sputum sol phase samples of chronic bronchitis patients without an infection (median $66.7 \mathrm{mg} \cdot \mathrm{L}^{-1}$, $\mathrm{n}=13$ ).

No significant correlation was found between the concentrations of $\operatorname{sIgA}$ and lactoferrin in the sputum sol phase in chronic bronchitis patients with $(\mathrm{r}=0.19)$ or without $(\mathrm{r}=0.55)$ an $H$. influenzae infection. In patients with bronchial asthma, this correlation was significant $(\mathrm{r}=$ 0.67, $\mathrm{p}=0.02$ ) (fig. 6).

\section{Discussion}

The concentrations of transferrin in the sputum sol phase and the Q-values of transferrin as well as of albumin were increased in chronic bronchitis patients with an $H$. influenzae infection compared to those without an infection and those with bronchial asthma, indicating that the increased transudation of these serum proteins in the infected patients is due to the infection (figs. 1 and 2). A higher transudation of albumin in infected patients with chronic bronchitis compared to uninfected patients has also been described by STOCKLEY et al. [4] and BurnetT and StOCKLEy [26]. Some evidence has been presented that albumin is locally produced and actively transported $[27,28]$ but it is uncertain whether this also applies for humans. If so, Q-values $>1$ are even more remarkable. A wide range of $\mathrm{Q}$-values was observed for transferrin and albumin in each group of patients. This wide range in individual values is in agreement with the data of Wiggins et al. [29] and SchoonBrood et al. [30] on the Q-values for albumin in sputum sol phase of patients with various pulmonary diseases. Part of the large spread may be caused by dilutional errors, since sputum may contain saliva [4].

The observation that the median RCE for transferrin in the infected patients is higher than 1.0 (fig. 3) indicates that transferrin reaches the bronchial lumen not only by passive diffusion but also by local production or active transport through the epithelial layer. Human peripheral blood lymphocytes may contribute to the local production of transferrin since they synthesize and secrete transferrin [31]. Moreover, it has been shown that T-lymphocyte infiltration is amplified in patients with chronic bronchitis $[32,33]$ and the T-lymphocytes are also attracted during infection.

The concentrations of lactoferrin in sputum sol phase samples from chronic bronchitis patients with and without an $H$. influenzae infection and patients with bronchial asthma were not different. This was a remarkable result since the concentration of $\operatorname{sig} \mathrm{A}$ was higher in the sputum sol phase of chronic bronchitis patients with an $H$. influenzae infection compared to chronic bronchitis patients without an infection and patients with bronchial asthma (fig. 4). BROGAN et al. [34] found similar concentrations of lactoferrin in the sputum of patients with bronchitis and patients with asthma both with an exacerbation, but the infection state of these patients was not described. STOCKLEY and BuRnetT [15] found elevated concentrations of $\operatorname{sig} \mathrm{A}$ in sputum samples of infected patients with chronic bronchitis compared to sputum samples of uninfected patients with chronic bronchitis, but they also did not identify the infecting micro-organisms. So, the lack of correlation between the concentrations of $\operatorname{sig} \mathrm{A}$ and lactoferrin in the patients with chronic bronchitis (fig. 5) and the separate data on sIgA and lactoferrin concentrations reported in the literature indicate that the production of lactoferrin and sIgA is not stimulated proportionally. The production of $\operatorname{sIgA}$ by the bronchial epithelium may be stimulated by the specific immune response, whereas the production of lactoferrin by the bronchial epithelium [12] may be less stimulated than that of sIgA during infection. The production of lactoferrin by the bronchial epithelium [12] and by neutrophilic granulocytes [13] may be compensated by binding of lactoferrin to H. influenzae [11], resulting in similar concentrations of lactoferrin in the sputum of chronic bronchitis patients with or without an infection and in patients with bronchial asthma.

THOMPSON et al. [35] found that lactoferrin levels in bronchoalveolar lavage fluid were elevated in patients with chronic bronchitis compared to healthy controls. Our results from analyses of sputum samples from patients with chronic bronchitis and from patients with bronchial asthma combined with the data of THOMPSON et al. [35] indicate that the concentrations of lactoferrin are elevated in airway secretions in patients with chronic bronchitis and patients with bronchial asthma, compared to healthy controls.

Transferrin and lactoferrin are high-affinity ironbinding proteins. Lactoferrin has antibacterial activity $[36,37]$ and anti-inflammatory properties [38]. A number of successful pathogens, including $H$. influenzae, are able to use these iron-binding proteins for their supply 
of iron, an essential growth factor [9, 10], thereby circumventing the antibacterial properties of lactoferrin. Based on our finding that the concentration of transferrin is higher during than in the absence of an infection, we hypothesize that after stimulation of the inflammatory response, transferrin provides $H$. influenzae with iron for growth. The degree of iron saturation of transferrin present in the respiratory tract is not known. However, serum transferrin is 30\% iron saturated [9], and since the transferrin is mainly serum derived, the degree of iron saturation is probably $30 \%$. In addition, the total amount of iron present in the sputum sol phase of patients with chronic bronchitis was sufficient to provide at least $50 \%$ iron saturation of the transferrin. During inflammation, the lactoferrin available in patients with chronic bronchitis may become important, when the $\mathrm{pH}$ drops due to the metabolic activity of invading microorganisms or metabolically stimulated leucocytes [37]. Lactoferrin retains a high affinity for iron at $\mathrm{pH}$ values $<4.5$, unlike transferrin, which loses its affinity for iron at $\mathrm{pH}<5.0$. At a low $\mathrm{pH}$, lactoferrin may even obtain iron by exchange from transferrin [39]. Since in sputum the concentrations of lactoferrin are similar as those of transferrin (figs. 1 and 4), the iron exchange between transferrin and lactoferrin may result in considerable iron saturation of lactoferrin. All $H$. influenzae strains tested have been shown to express transferrin receptors [11] which allow these bacteria to grow in the absence of free iron $[10,40]$. In another study, we observed that $H$. influenzae also binds human lactoferrin specifically and that the iron from lactoferrin is used for growth of $H$. influenzae [41]. The results from that study also indicate that the concentrations of transferrin and lactoferrin as measured in the sputum samples from patients with chronic bronchitis are sufficient for growth stimulation of $H$. influenzae.

The increased growth stimulation of $H$. influenzae in the sputum sol phase of infected and uninfected patients with chronic bronchitis compared to growth stimulation in the sputum sol phase of patients with bronchial asthma indicates that the sputum sol phase of chronic bronchitis patients contains factors promoting bacterial growth. The increased levels of transferrin in the sputum sol phase of chronic bronchitis patients may be this factor during an $H$. influenzae infection. Growth in sputum suggests that the conditions in the respiratory tract of these patients are favourable for bacterial infection.

We conclude that the concentrations of transferrin are increased in the sputum of patients with chronic bronchitis during an infection with Haemophilus influenzae compared to the sputum of patients with chronic bronchitis without an infection and patients with bronchial asthma. The concentrations of lactoferrin in the sputum of chronic bronchitis patients and in the sputum of patients with bronchial asthma are not different but are increased compared to healthy controls.

Acknowledgements: The authors would like to thank the members of the Dept of Pulmonology of the Academic Medical Center for their contribution in obtaining serum and sputum samples. They also thank J. Oosting for helpful comments on the statistical analysis of the data and W. van de Eshof for determination of the iron content of sputum sol phase.

\section{References}

1. Groeneveld K, Van Alphen L, Eijk PP, Visschers G, Jansen HM, Zanen HC. Endogenous and exogenous reinfections by Haemophilus influenzae in patients with chronic obstructive pulmonary disease; the effect of antibiotic treatment upon persistence. J Infect Dis 1990; 161: 512-517.

2. Murphy TF, Sethi S. Bacterial infection in chronic obstructive pulmonary disease. Am Rev Respir Dis 1992; 146: 1067-1083.

3. Groeneveld K, Eijk PP, Van Alphen L, Jansen HM, Zanen HC. Haemophilus influenzae infections in patients with chronic obstructive pulmonary disease despite specific antibodies in serum and sputum. Am Rev Respir Dis 1990; 141: 1316-1321.

4. Stockley RA, Mistry M, Bradwell AR, Burnett D. A study of plasma proteins in the sol phase of sputum from patients with chronic bronchitis. Thorax 1979; 34: 777-782.

5. Amitani R, Wilson R, Rutman A, et al. Effects of human neutrophil elastase and Pseudomonas aeruginosa proteinases on human respiratory epithelium. Am J Respir Cell Mol Biol 1991; 4: 26-32.

6. Hogg JC. Bronchial mucosal permeability and its relationship to airways hyperreactivity. J Allergy Clin Immunol 1981; 67: 421-425.

7. Persson CGA. Role of plasma exudation in asthmatic airways. The Lancet 1986; ii: 1126-1128.

8. Persson CGA, Erjefält I. Inflammatory leakage of macromolecules from the vascular compartment into the tracheal lumen. Acta Physiol Scand 1986; 126: 615-616.

9. Wooldridge KG, Williams PH. Iron uptake mechanisms of pathogenic bacteria. FEMS Microbiol Rev 1993; 12: 325-348.

10. Herrington DA, Sparling PF. Haemophilus influenzae can use human transferrin as a sole source for required iron. Infect Immun 1985; 48: 248-251.

11. Schryvers AB. Characterization of the human transferrin and lactoferrin receptors in Haemophilus influenzae. Mol Microbiol 1988; 2: 467-472.

12. Bowes D, Clark AE, Corrin B. Ultrastructural localization of lactoferrin and glycoprotein in human bronchial glands. Thorax 1981; 36: 108-115.

13. Masson PL, Heremans JF, Schonne E. Lactoferrin, an iron-binding protein in neutrophilic leukocytes. $J$ Exp Med 1969; 130: 643-658.

14. Van de Graaf EA, Out TA, Kobesen A, Jansen HM. Lactoferrin and secretory IgA in the bronchoalveolar lavage fluid from patients with a stable asthma. Lung 1991; 169: 275-283.

15. Stockley RA, Burnett D. Local IgA production in patients with chronic bronchitis: effect of acute respiratory infection. Thorax 1980; 35: 202-206.

16. Van de Graaf EA, Out TA, Jansen HM. The measuring of "respiratory-membrane permeability" and local production of immunoglobulins and antibodies by means of an analysis of sputum. In: Persson CGA, Brattsand $\mathrm{R}$, Laitinen LA, Venge P, Eds. Inflammatory Indices in Chronic Bronchitis. Agents and Actions Supplements. Birkhauser Verlag, Basel 1990; Vol.30: pp. 257-267.

17. Medical Research Council. Definition and classification of chronic bronchitis for clinical and epidemiological purposes. The Lancet 1965; 1: 775-779.

18. American Thoracic Society. Medical section of the American lung association. Standards for the diagnosis and care of patients with chronic obstructive pulmonary 
disease (COPD) and asthma. Am Rev Respir Dis 1987; 137: 225-243.

19. Groeneveld K, Van Alphen L, Van Ketel RJ, Geelenvan den Broek L, Eijk PP, Zanen HC. Nonculture detection of Haemophilus influenzae in sputum with monoclonal antibodies specific for outer membrane lipoprotein P6. J Clin Microbiol 1989; 27: 2263-2267.

20. Out TA, Jansen HM, Van Steenwijk RP, De Nooijer MJ, Van de Graaf EA, Zuijderhoudt FMJ. ELISA of ceruloplasmin and alpha-2-macroglobulin in paired bronchoalveolar lavage fluid and serum samples. Clin Chim Acta 1987; 165: 277-288.

21. Haaijman JJ, Deen C, Radl J. Determination of different molecular forms of human $\operatorname{IgA} 1$ and $\operatorname{IgA} 2$ with monoclonal antibodies. In: Facchini A, Haaijman JJ, Labo G, Eds. Immunoregulation in Aging. Eurage Rijswijk 1986; pp. 285-294.

22. Schoonbrood DFM, Out TA, Lutter R, Reimert CM, Van Overveld FJ, Jansen HM. Plasma protein leakage and local secretion of proteins assessed in sputum in asthma and COPD. The effect of inhaled corticosteroids. Clin Chim Acta 1995; 240: 163-178.

23. Van de Graaf EA, Jansen HM, Weber JA, Koolen MGJ, Out TA. Influx of urea during bronchoalveolar lavage depends on the permeability of the respiratory membrane. Clin Chim Acta 1991; 196: 27-40.

24. Felgenhauer K. Protein filtration and secretion at human body fluid barriers. Pflügers Arch 1980; 384: 9-17.

25. Wonnacott RJ, Wonnacott TH. Introductory Statistics. 4th Edn. New York, John Wiley \& Sons, 1985.

26. Burnett D, Stockley R. Serum and sputum $\alpha$-2-macroglobulin in patients with chronic obstructive airways disease. Thorax 1981; 36: 512-516.

27. Nahon JL. The regulation of albumin and alpha-fetoprotein gene expression in mammals. Biochimie 1987; 69: 445-459.

28. Price AM, Webber SE, Widdicombe JG. Transport of albumin by the rabbit trachea in vitro. J Appl Physiol 1990; 68: 726-730.

29. Wiggins J, Hill SL, Stockley RA. Lung secretion solphase proteins: comparison of sputum with secretions obtained by direct sampling. Thorax 1983; 38: 102-107.
30. Schoonbrood DFM, Lutter R, Habets FJM, Roos CM, Jansen HM, Out TA. Analysis of plasma-protein leakage and local secretion in sputum from patients with asthma and chronic obstructive pulmonary disease. Am J Respir Crit Care Med 1994; 150: 1519-1527.

31. Soltys HD, Brody JJ. Synthesis of transferrin by human peripheral blood lymphocytes. J Lab Clin Med 1970; 75: 250-257.

32. Puci A, Clancy R, Jackson G. Quantitation of T-lymphocyte subsets in human bronchus mucosa. Am Rev Respir Dis 1982; 126: 364-366.

33. Fournier M, Lebargy F, Le Roy Ladurie F, Lenormand E, Pariente R. Intraepithelial T-lymphocyte subsets in the airways of normal subjects and patients with chronic bronchitis. Am Rev Respir Dis 1989; 140: 737-742.

34. Brogan TD, Ryley HC, Neale L, Yassa J. Soluble proteins of bronchopulmonary secretions from patients with cystic fibrosis, asthma and bronchitis. Thorax 1975; 30 : 72-79.

35. Thompson AB, Bohling T, Payvandi F, Rennard SI. Lower respiratory tract lactoferrin and lysozyme arise primarily in the airways and are elevated in association with chronic bronchitis. J Lab Clin Med 1990; 115: 148-158.

36. Bullen JJ, Armstrong JA. The role of lactoferrin in the bactericidal function of polymorphonuclear leukocytes. Immunology 1979; 36: 781-791.

37. Weinberg ED. Iron withholding: a defense against infection and neoplasia. Physiol Rev 1984; 64: 65-102.

38. Veerhuis R, Kijlstra A. Inhibition of hemolytic complement activity by lactoferrin in tears. Exp Eye Res 1982; 34: 257-265.

39. Van Snick JL, Masson PL, Heremans JF. The involvement of lactoferrin in the hyposideremia of acute inflammation. J Exp Med 1974; 140: 1068-1084.

40. Pidcock KA, Wooten JA, Daley BA, Stull TL. Iron acquisition by Haemophilus influenzae. Infect Immun 1988; 56: 721-725.

41. Vogel L, Geluk F, Jansen H, Dankert J, van Alphen L. Human lactoferrin receptor activity in nonencapsulated Haemophilus Influenzae. FEMS Microbiol Letters 1997; (in press). 